\title{
O DESENHO INFANTIL NA ÓTICA DA ECOLOGIA DO DESENVOLVIMENTO HUMANO
}

\author{
Luciane Germano Goldberg \\ Maria Angela Mattar Yunes" \\ José Vicente de Freitas
}

RESUMO. Este trabalho resultou de reflexões sobre a Abordagem Ecológica do Desenvolvimento Humano de Urie Bronfenbrenner associada ao pensamento de estudiosos da Educação Ambiental. O foco deste artigo será compreender a relação entre percepção, o desenho e o conceito de atividade molar na perspectiva ecológica de Bronfenbrenner. Pressupõe-se que o desenho é também uma forma de expressar criativamente a percepção que as crianças têm dos ambientes que habitam. Será ressaltada a importância da imaginação e potencial da expressão do desenho como importante ferramenta na construção de conhecimentos e integração de experiências originadas em contextos variados. Estas experiências gráficas fazem parte do crescimento psicológico e são essenciais para a formação de indivíduos sensíveis, criativos e capazes de transcender e transformar a realidade. Para trabalhar com estas idéias são exemplificados desenhos de crianças de uma ONG no Extremo Sul do Brasil que propõe educação ambiental através de arte-educação.

Palavras-chave: desenho infantil, ecologia do desenvolvimento, arte-educação.

\section{DRAWING IN CHILDHOOD AND THE ECOLOGY OF HUMAN DEVELOPMENT}

\begin{abstract}
This work is a result of reflexions on the Ecology of Human Development of Urie Bronfenbrenner associated to thoughts of Environmental Education scientists. The focus of this article is to understand the relation among perception, drawing and the concept of molar activity under the ecological perspective of Bronfenbrenner. We supposed that drawing is also a way to express with creativity the perception children have of their own environment. The importance of imagination and the potential of expression of drawing will be emphasized as a relevant tool to build knowledge and integrate experiences which are originally from different contexts. These graphic experiences are part of psychological evolution and are essential to raise sensitive and creative individuals who are able to transcend and transform reality. In order to work with these ideas we bring examples of children's drawings produced in a non governmental institution located in the extreme south of Brazil and we propose environmental education through art education.
\end{abstract}

Key words: Children's drawing, ecology of development, art education.

O desenho infantil é um dos aspectos mais importantes para o desenvolvimento integral do indivíduo e constitui-se num elemento mediador de conhecimento e autoconhecimento. A partir do desenho a criança organiza informações, processa experiências vividas e pensadas, revela seu aprendizado e pode desenvolver um estilo de representação singular do mundo.
O presente trabalho origina-se de um olhar investigativo em que o ponto de partida é a arteeducação aliada aos princípios da Educação Ambiental. Foram utilizados alguns conceitos da abordagem ecológica de desenvolvimento humano de Urie Bronfenbrenner (1979/1996) como base teórica para observação e análise de desenhos infantis realizados no contexto de uma ONG. Esses desenhos

\footnotetext{
* Arte-educadora e mestre em Educação Ambiental pela Fundação Universidade Federal do Rio Grande - FURG/RS.

\# Doutora em Educação: Psicologia da Educação pela Pontifícia Universidade Católica de São Paulo. Coordenadora do Centro de Estudos Psicológicos sobre Meninos e Meninas de Rua. Departamento de Educação e Ciências do Comportamento Fundação Universidade Federal do Rio Grande.

II Doutor em História e Sociedade pela UNESP. Coordenador e docente do curso de Pós Graduação em Educação Ambiental da Fundação Universidade Federal do Rio Grande - FURG/RS.
} 
configuram-se nesta pesquisa como expressão da percepção que as crianças têm dos ambientes que habitam. Para Bronfenbrenner (1979/1996), estamos em constante crescimento psicológico a partir das relações de reciprocidade, sentimento afetivo positivo e equilíbrio de poder (1996) que se desenvolvem entre pessoas e entre pessoas e os seus ambientes. Desta forma, o desenho infantil pode emergir como uma atividade molar que faz o elo de representação destas relações e de outras vivências significativas para o desenvolvimento social, afetivo e cognitivo (Goldberg, 2004).

\section{APRESENTANDO A ABORDAGEM ECOLÓGICA DE DESENVOLVIMENTO HUMANO}

Pensar e ver o mundo ecologicamente significa abrir nossas percepções para um mundo complexo, vivo, dinâmico e intenso. Nesse mundo existem muitos vetores em constante e mutante interação que contribuem incessantemente para o nosso desenvolvimento psicológico. Buscar conhecimentos sobre a relação homem/ambiente, contextualizar suas perspectivas de interações/transações (Yunes, 2001) e refletir sobre as possibilidades de desenvolvimento saudável requerem a compreensão de um ser humano inserido em diferentes ambientes proximais e distais. Sendo assim, Urie Bronfenbrenner (1979/1996, 1998) sabiamente nos ajuda a ver e pensar o mundo a partir de um referencial teórico definido inicialmente a partir da "forma como a pessoa percebe e lida com o seu ambiente" (Bronfenbrenner, 1979/1996, p. 5). Para ele o meio ambiente ecológico é constituído por uma série de estruturas, encaixadas uma dentro da outra, representando os diferentes meios em que o indivíduo transita, de forma direta ou indireta. Estes ambientes atuam como sistemas de influência na construção das suas identidades. Nesta abordagem, todos os ambientes estão inter-relacionados e o importante é a maneira como a pessoa percebe os ambientes e interage dentro deles e com eles.

A pessoa é uma entidade em crescimento e está se desenvolvendo constantemente a partir das relações de reciprocidade criadas entre ela e os diferentes ambientes que habita. Para Bronfenbrenner (1979/1996), o meio ambiente não se limita a um único ambiente imediato, mas inclui a interconexão entre os ambientes que sofrem influências internas e externas oriundas de meios mais amplos. É relevante apontar no conceito de meio ambiente a visão sistêmica, em que todos os elementos envolvidos no contexto cotidiano do indivíduo em desenvolvimento são importantes. Muitas pesquisas nas áreas da
Psicologia e da Educação foram realizadas fora do contexto, buscando reproduzir situações artificiais em laboratório; porém, para se estudar o indivíduo em desenvolvimento é preciso apreender seu contexto, suas atividades cotidianas, e compreender suas percepções. Com base nestas idéias, Portugal (1992) afirma:

$\mathrm{Na}$ investigação ecológica as propriedades do sujeito e do meio, as estruturas ambientais e os processos que ocorrem nelas e entre elas, devem ser vistos como interdependentes e analisados em termos sistêmicos. Apenas deste modo, podemos identificar o processo de interação mútua entre o sujeito em desenvolvimento e o mundo em transformação (p. 50).

Para uma melhor compreensão deste dinamismo apresentaremos alguns conceitos-chaves da abordagem ecológica de desenvolvimento humano, que incluem primeiramente os contextos de desenvolvimento e o meio ambiente ecológico. Para Bronfenbrenner (1979/1996), os sistemas que compõem e organizam o meio ambiente constituem-se pelo encaixe de estruturas concêntricas denominadas microssistema, mesossistema, exossistema e macrossistema, que compreendem, além do comportamento dos indivíduos, as conexões entre outras pessoas, a natureza dos vínculos e a influência direta ou indireta sobre a pessoa em desenvolvimento nos contextos em que ela habita e atua de forma ativa. $\mathrm{O}$ microssistema se refere aos ambientes em que a pessoa convive mais diretamente, como a família, a escola ou o ambiente de trabalho. O mesossistema representa as inter-relações existentes entre dois ou mais ambientes (microssistemas) em que a pessoa participa de forma ativa. $\mathrm{O}$ exossistema caracteriza-se por um ou mais ambientes que não envolvem a pessoa como um participante ativo, mas que exercem ou sofrem influência de eventos que acontecem no ambiente imediato em que a pessoa atua. $\mathrm{O}$ macrossistema se compõe de valores culturais, crenças, aspectos históricos, sociais, ideológicos que afetam os outros sistemas, caracterizando padrões generalizados e determinando propriedades específicas dos exo, meso e microssistemas.

Como se pode ver, Bronfenbrenner expande a visão sobre ecologia e meio ambiente, comumente pensada apenas na área das ciências naturais. Castro (1992) busca a origem etimológica da palavra ecologia, constituída por dois termos gregos: oikos, que significa habitação, família e logia, que significa 
dizer, ler, anunciar. A partir daí ele percebe que não há referência à natureza, como a maioria das pessoas costuma pensar, mas à habitação, implicando o sentido do homem e do universo em seu ser. Partindo deste raciocínio podemos então "ver com outros olhos" a relação do ser humano com o meio onde ele vive. Habitamos muitos lugares, desde o nosso corpo, a nossa casa, cidade, país, continente, planeta, universo... Sendo assim, a questão ecológica reside também nas relações dos indivíduos a partir da habitação destes ambientes e nas dinâmicas interações entre os mais variados espaços mentais, sociais e geográficos. O homem constrói seu universo, habita os espaços e projeta ações, configurando um cenário social e cultural específico em cada região.

\section{COMPREENDENDO O MICRO, MESO, EXO E MACROSSISTEMAS NOS DIAS ATUAIS}

É preciso pensar na atual estrutura social do Ocidente e nas oportunidades oferecidas para que as pessoas possam se desenvolver com êxito. Numa sociedade capitalista, êxito é sinônimo de condição que permita adquirir objetos de desejo e de consumo. Pela forma como essa sociedade está estruturada somente uma pequena parcela das pessoas tem a oportunidade de alcançar tais objetivos.

É preciso pensar de forma ecológica, analisar as relações entre os diferentes sistemas, pois as "condições sócio-econômicas, as tensões do emprego, o planejamento urbano, o sistema de transporte, o poder hipnótico da televisão, e outros fatores, são circunstâncias determinantes do funcionamento famliar" (Portugal, 1992, p. 116) e sujeitos à "toxicidade" de outros ambientes sociais (Garbarino, 1995).

Se pensarmos que a família (microssistema) é um dos núcleos mais importantes para o desenvolvimento dos indivíduos, é de extrema importância atentar para as relações existentes entre as crianças e os adultos que as rodeiam no ambiente familiar. Que tipo de indivíduo se forma em famílias em que não há tempo para o diálogo ou para atividades em conjunto? A palavra-chave é oportunidade. Oportunidade para muitas interações ou "interacionamentos", conforme propõem Yunes, Miranda e Cuello (2004). Na vida em família, é preciso oportunizar que a criança "veja" mais do que televisão, pois segundo Bronfenbrenner (1979/1996), a televisão tem origem em fontes externas que constituem parte do exossistema, por isso reproduzem idéias, disseminam ideologias e modos de vida (macrossistema), podendo ser responsável pelo isolamento da criança de contatos significativos com outras crianças e adultos. Para o autor da abordagem ecológica, é importante que o indivíduo participe e interaja nos mais variados contextos, o que intensifica seu desenvolvimento, permitindo que se desenvolvam novas competências cognitivas e sociais. Além disso, a comunicação entre os ambientes é de extrema importância e é uma importante dimensão do mesossistema:

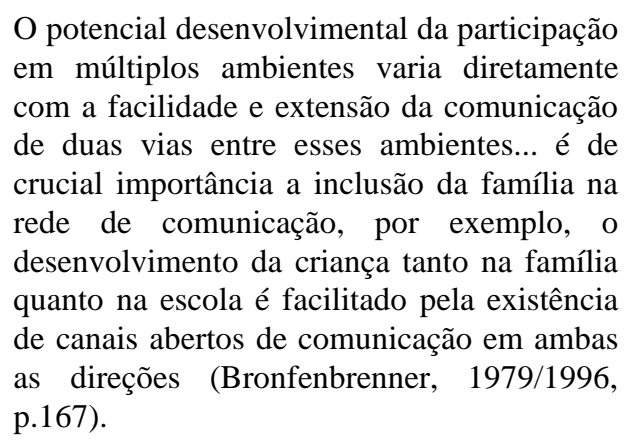

Se a comunicação e a integração entre ambientes comuns à pessoa em desenvolvimento são um fator estimulante ao crescimento psicológico, podemos pensar as influências da desconexão atual entre a escola e a família. Nossas experiências no trabalho com escolas ilustram a deficiência na comunicação inter-ambientes. Neste espaço de integração entre segmentos tão importantes, não se tem contato com pais ou responsáveis, pois este espaço de diálogo não existe dentro da escola a não ser nos dias de entrega de avaliações.

A escola parece estar "de costas" para a família e para a comunidade. Poucos pais acompanham as atividades escolares de seus filhos, o que em princípio impossibilita um canal de comunicação e integração das atividades escolares e domésticas. Assim, escola e família são mundos completamente diferentes em que a criança assume papéis distintos e fechados em cada contexto. Se somos o resultado de nossas vivências, que experiência significativa se leva da escola hoje, ainda centrada no sistema tradicional? Isso responde e justifica o desinteresse dos jovens pela escola?

Falar do mesossistema escola e família significa considerar elementos essenciais para o desenvolvimento dos indivíduos, pois tanto a família como a escola são ambientes formadores de atitudes, opiniões, valores, crenças e ideologias. Nos dias atuais, a escola tem sido cada vez mais responsável pela educação de valores fundamentais e condutas pró-sociais como amor, solidariedade, compaixão, respeito ao próximo e ao ambiente. Essa mesma escola parece não estar preparada para uma educação integral e sistêmica, pois sua estrutura fragmentada e 
impessoal não lhe permite "pensar ecologicamente" o desenvolvimento humano e sua responsabilidade e compromisso com esta questão. Os professores dificilmente terão experimentado uma vivência diferente daquela que reproduzem, e revelam uma necessidade de reflexão e aprendizado de novas práticas educativas, construídas de forma coletiva.

Pensando maior e retornando à estrutura social atual, percebe-se que estes problemas refletem um sistema mais amplo, que comanda comportamentos, pensamentos e tomadas de decisão. No nível do macrossistema está um projeto de civilização moderna do qual ainda sofremos fortes conseqüências. Um projeto em que a ciência, calcada na razão, responde a todas as questões da humanidade, a sensibilidade é considerada supérflua. Foi criada uma nova natureza, a natureza humana, que precisa se distanciar do grotesco mundo natural, demonstrar superioridade. Com a modernidade o homem passa a ser o centro do universo, comandando e guiando a carruagem dos tempos. Muitas glórias se têm deste processo civilizador, mas também muitas desgraças, pois se construiu uma mentalidade individualista e antropocêntrica. Se nada impõe limites à humanidade, se tudo se torna possível, até recriar a própria espécie, não há muito de que se espantar em alguns comportamentos da sociedade pós-moderna. Com essa idéia de civilização surge a educação, responsável pela adequação das pessoas a este projeto social.

Vivemos a era em que tudo é possível, a era do individualismo, da violência e da apatia. A mídia é responsável pela banalização da vida, pois assistir a uma chacina no telejornal tornou-se comum. Ninguém mais se choca com assassinatos e tragédias, desde que suas vidas estejam fora desses problemas. Tudo é facilmente produzido, o terrorismo e a guerra são exemplos, como se a humanidade já não tivesse presenciado o suficiente nas duas grandes guerras mundiais.

Estamos vivendo um período de transição e mudança de valores, mas não podemos deixar de analisar que valores estão emergindo dessa nova sociedade pós-moderna: a descartabilidade? A apatia? A desigualdade? A arrogância? Frente a um colapso socioambiental, que surge como uma bomba-relógio pronta para ser detonada, é essencial a convergência de idéias e ações para a solução dos problemas, ainda que no nível cotidiano das pessoas. A abordagem ecológica de Bronfenbrenner nos alerta para a importância do contexto no desenvolvimento humano, afasta-nos das concepções inatistas e nos mostra o conjunto de energias e vetores que influenciam e constituem novos indivíduos, aqueles que, como nós, são responsáveis pelo futuro da humanidade. Compreendendo os contextos, do micro ao macrossistema e identificando os principais vetores responsáveis pela construção dos indivíduos é possível intervir na esfera das políticas públicas e proporcionar oportunidades de participação da comunidade na tomada de decisões e na solução de problemas socioambientais. Este é um processo lento que necessita da intervenção dos mais variados meios, especialmente da mídia, tão presente no cotidiano da maioria da população.

\section{A IMPORTÂNCIA DO RESGATE DAS SINGULARIDADES}

Há muito que se pensar e é preciso dar oportunidade para que crianças e adolescentes possam participar de atividades de cooperação, solidariedade e ajuda, e não apenas de jogos de violência ou competição, presentes no seu cotidiano. Quantos dos nossos jovens serão capazes de examinar os acontecimentos locais e globais de forma crítica? Quantos perceberão as relações existentes entre suas vidas e o sistema econômico? Quantos conseguirão conhecer seu poder político individual e coletivo? Quantos terão consciência de si e de suas potencialidades? Que subjetividades estão sendo construídas?

Desta forma pode-se perceber a importância de se resgatarem as singularidades do indivíduo, de promover seu autoconhecimento. Para Guattari (1991), deve haver uma revolução planetária, não só em escala visível, mas também no nível da sensibilidade, da inteligência e do desejo. Segundo o autor, deveria haver uma recomposição da práxis humana nos mais variados domínios e em todas as escalas (individuais e coletivas) no próprio cotidiano, uma mudança fundamental das mentalidades em busca das singularidades, de novas práticas, estéticas por meio de um trabalho potencial de subjetivação. Deve haver a instauração de novos sistemas de valorização, percepção e expressão.

Em consequiência da globalização assistimos à dissolução de muitas crenças e costumes de comunidades tradicionais em modos de vida pasteurizados e moldados ao sabor de uma cultura homogeneizada, sem identidade própria. É preciso resgatar a singularidade, em oposição à individualidade que trancafia pensamentos, isola mentes, proíbe contatos mais intensos.

Loubet (1979) confirma estas idéias apontando a importância da singularidade do indivíduo no desenvolvimento da cultura de um povo: "Uma 
identidade cultural só é mantida e desenvolvida quando as peculiaridades internas de um povo o singularizam. Só este cunho pessoal, individualizante, oferece um contraponto equilibrante no processo de integração da segunda natureza do homem, a cultura" (p. 28).

Não podemos então deixar de pensar na responsabilidade da constituição de subjetividades dos indivíduos com desenvolvimento psicológico sadio (Bronfenbrenner, 1990, 1991, Yunes e cols., 2004), se somos, ao mesmo tempo, agentes e objetos da cultura e tudo o que produzimos e construímos, constitui um modo de vida que tem uma subjetividade, que se amplia do individual para o coletivo numa escala macro, construindo padrões comportamentais e atitudinais de ação e transformação do mundo. Entendemos que o desenvolvimento psicológico sadio se dá a partir de interações com um ou mais adultos que queiram o bem incondicional das crianças que estão sob seus cuidados (Bronfenbrenner, 1991).

Guattari (1992) afirma que a subjetividade pode ser definida como "o conjunto de condições que torna possível que instâncias individuais e/ou coletivas estejam em posição de emergir como território existencial, em adjacência ou em relação de delimitação com uma alteridade ela mesma subjetiva" (p. 19).

A partir dessas idéias pode-se perceber que, em semelhança à teoria ecológica de Bronfenbrenner, esta proposição explicita a presença de objetos, atividades e especialmente outras pessoas, que emitem linhas de força, valências e vetores que atraem e repelem e orientam o comportamento e o desenvolvimento das pessoas em direção ao crescimento psicológico. São os processos proximais primários, definidos por Bronfenbrenner e Morris (1998) como os verdadeiros motores do desenvolvimento psicológico. É como se existisse em cada pessoa um mundo virtual que pode ser exteriorizado pela linguagem, seja ela gráfica, escrita ou falada, na medida em que fatos, acontecimentos ou outras pessoas provocam sua expressão. A subjetividade de cada um se constrói, então, pelos processos gerados nessa tensão entre o indivíduo e seus ambientes de atuação. Segundo Guatarri (1992):

De uma maneira mais geral, dever-se-á admitir que cada indivíduo, cada grupo social veicula seu próprio sistema de modelização da subjetividade, quer dizer, uma certa cartografia feita de demarcações cognitivas, mas também míticas, rituais, sintomatológicas, a partir da qual ele se posiciona em relação aos seus afetos, suas angústias [...] (p. 21/22).

Assim, acreditamos que temos necessidade de expressar nossa subjetividade, por qualquer via, artística ou não. A linguagem artística permite um devir criador que tem um papel importante na construção das identidades individuais e coletivas, podendo resgatar a singularidade perdida nas massas sem face do mundo contemporâneo.

\section{SERIA O DESENHO UMA ATIVIDADE MOLAR?}

Nesta parte do trabalho pretende-se direcionar conceitos da abordagem ecológica para o desenvolvimento de uma sensibilidade estética apurada. Esta pode ser exteriorizada por uma linguagem que revela a percepção do indivíduo sobre os diferentes ambientes que ele habita. Estudar o desenho como um elemento que define a percepção do indivíduo sobre seus ambientes não deve ser preocupação exclusiva de arte-educadores, mas sim de todos voltados para o desenvolvimento do grafismo infantil, que pode ser facilmente interrompido à medida que a criança passa a habitar o microssistema escola.

Segundo Bronfenbrenner (1979/1996), "uma atividade molar é um comportamento contínuo com um movimento ou tensão próprios, percebido pelo sujeito como tendo um significado ou intenção" (p. 59). A atividade molar é de complexidade variável, podendo invocar objetos, pessoas e acontecimentos não concretamente presentes no ambiente imediato. A invocação pode ser realizada através de conversas, de contar estórias, da representação pictórica, ou de uma variedade de outros meios. Sendo assim, deduz-se que o desenho pode ser considerado uma atividade molar, pois é caracterizado por uma intenção e significados próprios e traz em seu conteúdo fatos, pessoas e conhecimentos percebidos.

A maioria dos indivíduos na infância começa a comunicar-se graficamente por meio do desenho, independentemente de raça, sexo ou nacionalidade. Basta um pedaço de papel e um giz de cera que tudo se transforma em magia e brincadeira, nas mais belas formas do desenho, como um processo "natural" de desenvolvimento. Se todos os indivíduos continuassem o processo de desenvolvimento gráfico, passando por todas as etapas, com certeza saberiam se expressar a partir de manifestações artísticas. No entanto, sabe-se que a realidade é outra e a maioria dos adultos teve seu processo de desenvolvimento gráfico interrompido em alguma 
etapa fundamental. Dentre as muitas teorias relativas às etapas do desenvolvimento gráfico infantil, Lowenfeld (1977) e Kellog (1985) trazem estudos importantes com relação à evolução do grafismo. Segundo eles existem etapas fundamentais comuns a todas as crianças, porém cada criança, de acordo com a sua educação e o meio social em que vive apresenta um ritmo processual distinto.

O desenho é um importante meio de comunicação e representação da criança e apresenta-se como uma atividade fundamental, pois a partir dele a criança expressa e reflete suas idéias, sentimentos, percepções e descobertas. Para a criança o desenho é muito importante, é seu mundo, é sua forma de transformálo, é seu meio de comunicação mais precioso. Nele estão muitos de seus medos, de suas vontades, de suas carências e de suas realizações. Tudo o que está ao redor interage, criando um sistema de representação muito rico e de extrema relevância para a criança (Goldberg, 1999).

De acordo com Derdik (1989), a criança, por meio do desenho, interage com o meio ambiente, experiencia novas realidades e as compartilha com o mundo:

O desenho constitui para a criança uma atividade total, englobando o conjunto de suas potencialidades. Ao desenhar, a criança expressa a maneira pela qual se sente existir. O desenvolvimento do potencial criativo na criança seja qual for o tipo de atividade em que ela se expresse, é essencial ao ciclo inato de crescimento. Similarmente, as condições para o seu pleno crescimento (emocional, psíquico, físico, cognitivo) não podem ser estáticas (p.52).

O desenho faz parte deste crescer, deste desenvolver-se, além de falar, andar, comer, entre outras habilidades que são aprendidas desde o nascimento. As atividades molares ocorrem nos microssistemas, mas por serem capazes de invocar pessoas, objetos e acontecimentos fora do contexto imediato, revelam uma interconexão entre diferentes contextos, constituindo o que o autor denomina de mesossistema mental. Segundo Vygotsky, em Oliveira (1995), a capacidade do indivíduo de lidar com representações que substituem o próprio real possibilita que ele se liberte do espaço e tempo presentes, fazendo relações mentais na ausência das coisas, imaginando, fazendo planos e tendo intenções. Para o autor, as representações mentais da realidade exterior são, na verdade, os principais mediadores a serem considerados na relação do homem com o mundo. Indo mais longe neste conceito,
Bronfenbrenner (1979/1996) aponta a possibilidade de intervenção no meio ambiente por parte da criança:

As atividades molares emergentes da criança refletem o alcance e a complexidade crescentes do meio ambiente ecológico percebido, tanto dentro quanto além do ambiente imediato, assim como a crescente capacidade da criança de manejar e alterar seu meio ambiente de acordo com suas necessidades e desejos (p. 39).

É então fundamental preencher o imaginário das crianças com imagens cotidianas recheadas de significados poéticos, possibilitando um contato mais sensível com os ambientes em que elas vivem natural ou construído - através dos sentidos, como o tato e a visão, partindo de um autoconhecimento para o conhecimento do outro.

Se o foco do estudo sobre o indivíduo em seu contexto na abordagem ecológica do desenvolvimento humano está na forma como ele o percebe, o desenho se apresenta como um importante veículo de expressão da criança, através do qual ela pode exteriorizar sua percepção de si, do outro e do mundo:

A noção de percepção está comprometida com a noção de imagem. Esta propicia um feixe de significações do percebido. Podemos elevar o sentido do olhar e do desenhar às idéias de "fábrica de imagens", ou então "fábrica de significações (Derdik, 1989, p. 112).

O desenho "fábrica de imagens" conjuga elementos oriundos do domínio da observação sensível do real e da capacidade de imaginar e projetar, vontades de significar. O desenho configura um campo minado de possibilidades, confrontando o real, o percebido e o imaginário. A observação, a memória e a imaginação são as personagens que flagram essa zona de incerteza: o território entre o visível e o invisível (ibid. p.115).

Sendo assim, o desenho é uma interpretação que cria relações, constrói símbolos e revela conceitos. Para ilustrar algumas dessas idéias trazemos um relato sobre um exemplo de desenho infantil realizado por uma menina de 5 anos de idade:

Carolina $^{1}$ fez um desenho (Anexo A) para dar à professora quando acompanhada de

1 Nome fictício atribuído à aluna em questão. 
seus pais em uma visita à casa dela. No desenho aparecem um inseto grande e colorido e outros dois menores em uma única cor, sendo que um destes está depositando algo num círculo. Há também a presença de uma menina segurando um objeto quadrado com um desenho de um inseto dentro e uma linda nuvem sorridente. No momento em que a professora recebeu o desenho ficou tentando imaginar o que este cenário representava e logo em seguida sua mãe disse: a Carol agora está preocupada com a dengue, ela ganhou uma cartilha e vive falando sobre isso! No desenho, a menina carregava a cartilha da dengue e mais abaixo um mosquito estava depositando ovos numa poça d'água.

Aí está um exemplo de que num simples desenho temos muitas informações que revelam não só o ambiente imediato da Carolina, mas uma campanha contra a dengue que acontece em todo o território nacional. Isso demonstra o poder da informação, da mídia, de campanhas bem-feitas e da importância de o setor público divulgar conhecimentos sobre a dengue, desde sua contaminação pelo mosquito e proliferação a procedimentos para evitá-la ou erradicá-la. Demonstra também que a partir desse desenho pode-se perceber que a criança aprende, observa e constrói conhecimentos que muitos adultos talvez não tenham. Através da representação gráfica, a menina de cinco anos mostra que está preocupada com a disseminação da doença, que "cuida" para que sua mãe tome as providências necessárias para impedir que o mosquito ponha seus ovos na água parada que se acumula nas casas. Daí a importância de enriquecer o cotidiano infantil com experiências significativas em contato com a natureza, em situações de cooperação e solidariedade.

Atividades de educação ambiental são fundamentais para a sensibilização nesse sentido, o que possibilita também o resgate de valores humanos essenciais. Bronfenbrenner (1979/1996) também destaca a importância do mundo da imaginação, da fantasia e da irrealidade não meramente como um reflexo da realidade, mas como um aspecto ativo, criativo o que nos faz perceber com maior intensidade a importância da expressão artística no processo de construção da subjetividade pessoal e coletiva e como importante elemento de conexão entre os diferentes ambientes onde habitamos. Complementando essas idéias, é essencial destacar a importância atribuída por Vygotsky (1966) à imaginação para o desenvolvimento do indivíduo:
A imaginação adquire uma função de suma importância na conduta e no desenvolvimento humano, convertendo-se em meio de ampliar a experiência do homem que, ao ser capaz de imaginar o que não havia visto, ao poder conceber, baseando-se em relatos e descrições aquilo que não experimentou pessoal ou diretamente, não está encerrado no círculo estreito da sua própria existência, podendo alargar, expandir seus limites assimilando, com a ajuda da imaginação experiências históricas ou sociais alheias (p.13).

Sendo assim, percebe-se o desenho como um canal para o exercício da imaginação, para expressão e construção da subjetividade da criança em desenvolvimento. Refletindo sobre a imaginação, que espaço temos na sociedade para seu exercício, principalmente no mundo adulto? Bronfenbrenner (1979/1996) afirma que o funcionamento efetivo dos processos de criação na família e nos outros ambientes requer políticas públicas e práticas que garantam lugar, tempo, estabilidade, status, reconhecimento, sistema de crenças, costumes e ações que apóiem as atividades de criar.

A arte-educação torna-se de extrema importância para a formação dos indivíduos, à medida que se tem como finalidade o desenvolvimento de uma consciência estética, pois, "compreende uma atitude mais harmoniosa e equilibrada perante o mundo em que os sentimentos, a imaginação e a razão se integram; em que os sentidos e os valores dados à vida são assumidos no agir cotidiano" (Duarte Junior, 1991, p. 73).

Ainda sobre a relação entre desenho, imaginação, imaginário e desenvolvimento humano, salientamos as idéias de Postic (1993), segundo as quais pelo imaginário voltamos às fontes de nós mesmos e ao mesmo tempo evadimo-nos de nós para buscar nossa amarração no universo. Quanto à expressão das chamadas atividades molares na concepção da abordagem ecológica, as idéias de Postic parecem ir ao encontro das de Bronfenbrenner, ao afirmar que:

Desenhar, narrar um fato são formas de ação, de domínios sobre a emoção: modela-se o próprio real. A pessoa pode ser invadida e mergulhada em imagens e sonhos, e ficar paralisada por eles. Em compensação, se ela conseguir dominar a explosão dessas imagens e sonhos, se possuir um modo de utilizá-los através dos jogos ou das formas, chegará à criação (p.18). 
Sabe-se que existem muitos aspectos que levam uma criança a parar de desenhar antes de completar os estágios fundamentais do desenvolvimento gráfico infantil, fechando muitas vezes portas para o mundo perceptivo da representação e contemplação. Sendo assim, pesquisar a percepção que os indivíduos adultos têm dos ambientes que habitam a partir da representação gráfica, mais especificamente pelo desenho, demonstra a existência de uma barreira, visto que o público adulto, em sua grande maioria, afirma "não saber desenhar". Algumas pesquisas, como mostra Neiva-Silva (2003), utilizam a imagem fotográfica para coletar informações sobre a percepção das pessoas, pois ela permite o acesso a microssistemas pertencentes ao universo psicossocial dos sujeitos de pesquisa que não poderiam ser conhecidos de outra maneira, auxiliando na comunicação de significados mais facilmente atribuídos à imagem do que expressar pela linguagem falada ou escrita, dependendo do público que se deseje pesquisar.

O público alvo destas reflexões é constituído por crianças que estão em processo de desenvolvimento gráfico, no qual o desenho é fundamental para seu crescimento cognitivo e psicológico. Conforme já mencionado, um desenho pode contar muito mais que muitas palavras, pois nas suas criativas figuras carrega significados percebidos no ambiente vivenciados pela criança.

\section{A ONG PESQUISADA E OS DESENHOS INFANTIS: POETIZANDO O COTIDIANO}

As representações gráficas das crianças consideradas neste trabalho foram geradas a partir de atividades de educação ambiental no projeto intitulado "Ondas que te quero mar: educação ambiental para comunidades costeiras" de uma ONG denominada Núcleo de Educação e Monitoramento Ambiental NEMA, existente desde 1987 no Extremo Sul do Rio Grande do Sul. O NEMA desenvolve projetos em parceria com instituições públicas e privadas, apoiados em ações coordenadas de educação, monitoramento, pesquisa e conservação visando à gestão ambiental. A equipe de trabalho do NEMA é constituída por oceanólogos, geógrafos, arte-educadores, biólogos, professores de educação física, estagiários e voluntários, o que configura um ambiente multidisciplinar.

Durante muitos anos, profissionais do NEMA utilizaram o desenho das crianças como um indicador de avaliação das atividades de educação ambiental, como saídas de campo, palestras, oficinas de reciclagem, entre outras. Depois das atividades, as crianças participantes realizavam desenhos que constituíram um banco de imagens infantis muito rico $\mathrm{e}$ interessante. $\mathrm{O}$ aumento da sensibilidade à percepção a partir das atividades realizadas e a construção de conhecimento interdisciplinar são visíveis nos desenhos infantis. A análise destas produções gráficas permite-nos afirmar que, pela observação e contato mais aprofundado com os ambientes costeiros, os desenhos tornam-se mais detalhados, mais ricos em formas e cores e com informações ilustrativas do que foi aprendido. É claro que cada criança absorve o que mais lhe interessa, e esses aspectos se destacam com maior facilidade. A maioria das crianças até os 5 ou 6 anos de idade desenha com espontaneidade, expressando criativamente o que vivencia. A partir dessa idade pode-se perceber a influência da alfabetização e do ambiente escolar no "congestionamento" ${ }^{2}$ do desenvolvimento gráfico infantil, visto que, na maioria das vezes a criança substitui o sistema de representação do desenho pelo da escrita.

Peralta (1998) afirma que existem falhas no sistema educacional decorrentes da falta de informação quanto à origem comum do desenho e da escrita, o que ocasiona a substituição do sistema representacional do desenho pelo sistema da escrita:

Sabe-se que o nosso sistema educacional até o presente, com raras exceções, não reconhece a origem comum do desenho e da escrita, e por conseqüência, os nossos currículos de 20 e 30 graus não comportam uma base comum para a formação de profissionais que possam auxiliar os alunos em idade de formação pré-escolar em seu desenvolvimento harmônico nas interfaces da inicialização da linguagem simbólica (escrita) e a continuação da representação plástica. O que ocorre via - de - regra, é a substituição do sistema do desenho primeiro recurso comunicacional entre $o$ professor e o aluno em fase de pré-escola, pelo sistema da escrita, precariamente apoiado pela estereotipia gráfica (Peralta, 1998).

A escolarização é um dos principais fatores responsáveis pelo "congestionamento" da expressão gráfica, visto que é na escola que a criança passa a

2 Usou-se a expressão congestionamento para designar um processo que pode levar a criança, por vários motivos, a não acreditar no seu potencial criador que revela pelo desenho, desistindo de desenhar, interrompendo de vez seu desenvolvimento gráfico em uma das fases primordiais. 
maior parte de seu tempo. Em geral, as escolas tendem a passar uma única visão de mundo e há pouco espaço para a expressão fora das curtas aulas de Educação Artística. O sistema educacional transmite o conhecimento compartimentado e traz o empobrecimento da expressão gráfica.

Desenhar, contemplar e criar poetizam o cotidiano, ressignificam as atividades cotidianas, constroem novos sentidos para a vida. É preciso educar os sentidos como o olhar, para que se possa perceber a beleza existente ao nosso redor. A vida contemporânea é muito veloz e é preciso muita perspicácia para ver as mesmas imagens como se fossem novas a cada dia, pois, ao surgir o sol, não somos mais as pessoas de ontem, mas pessoas de hoje, que projetam o amanhã, o que pode ter um sabor todo especial e um colorido mágico.

\section{O QUE DÁ SENTIDO À VIDA}

A proposta da abordagem ecológica na sua completude e consistência traz uma análise de indivíduos em constante movimento de desenvolvimento, pois visualiza sistemicamente a sua inserção nos diferentes contextos. A complexidade e a influência das inter-relações entre os ambientes - do mais imediato ao mais distante - pelos quais a pessoa transita merecem especial atenção dos educadores. Desta forma, a questão ecológica reside não só nas interações dos/entre indivíduos a partir da sua habitação nos ambientes geográficos, mas também nas dinâmicas relações entre os mais variados espaços mentais e sociais.

É preciso pensarmos a importância da educação ambiental e do desenvolvimento humano munidos de uma sensível percepção dos ambientes onde nos inserimos. A partir de novas práxis educacionais, formais ou não formais, poderíamos resgatar a singularidade dos sujeitos, permitindo sua construção enquanto cidadãos capazes de participar de tomadas de decisão na esfera das políticas públicas e de reconhecer os problemas socioambientais atuais para os quais se buscam soluções individuais ou coletivas.

Convencidos da importância do desenho para o desenvolvimento da criança, é imprescindível estimular esta linguagem desde a mais tenra idade. Cabe principalmente à família e à escola ter clareza da importância deste processo fundamental, que não deve ser interrompido em nenhum dos dois contextos. É preciso disseminar o conhecimento sobre o desenvolvimento gráfico infantil nas escolas e na comunidade, pois somente assim as pessoas podem construir a consciência dos erros que podem estar cometendo, sem perceber suas conseqüências.

\section{REFERÊNCIAS}

Bronfenbrenner, U. (1990). Discovering what families do. Em D. Blankenhorn, S. Bayme \& J. B. Elshtain (Orgs.), Rebuilding the nest (pp. 27- 39). Wisconsin: Family Service America.

Bronfenbrenner, U. (1991). What do families do? Family Affairs, 4(1-2), 1-6.

Bronfenbrenner, U. (1996). A ecologia do desenvolvimento humano: Experimentos naturais e planejados. Porto Alegre: Artes Médicas. (Original publicado em 1979)

Bronfenbrenner, U. \& Morris, P. A. (1998, 5 ${ }^{\text {a }}$ ed.,). The ecology of developmental process. Em R. M. Lerner (Org.), Handbook of child psychology: Theoretical models of human development (pp. 993-1028). New York: John Wiley \& Sons.

Castro, M. A. de. (1992). Ecologia: a cultura como habitação. Em Soares, A. (Org). Ecologia e Literatura (pp.13-33). Rio de Janeiro: Tempo Brasileiro.

Derdik, E. (1989). Formas de pensar o desenho: desenvolvimento do grafismo infantil. São Paulo: Scipione.

Duarte Júnior, J. F. (1991, 6 ed.). Por que arte-educação? Campinas: Papirus.

Garbarino, J. (1995). Raising children in a socially toxic environment. San Francisco, Jossey-Bass Publishers.

Guattari, F. (1991, 3 ed.). As Três Ecologias. Campinas: Papirus.

Guattari, F. (1992). Caosmose: um novo paradigma estético. (A L. de Oliveira e L. C. Leão, Trad). São Paulo: Editora 34 (Coleção Trans).

Goldberg, L. G. (1999) Arte-Pré-Arte: um estudo acerca da retomada da expressão gráfica do adulto. Monografia de conclusão de curso Não-Publicada, curso de graduação em Educação Artística-licenciatura plena, Fundação Universidade Federal do Rio Grande.

Goldberg, L. G. (2004) Arte-Educação-Ambiental:o despertar da consciência estética e a formação de um imaginário ambiental na perspectiva de uma ONG. Dissertação de Mestrado Não-Publicada, Progarama de Pós-graduação em Educação Ambiental, Fundação Universidade Federal do Rio Grande.

Kellog, R. (1985). Analisis de la expresion plastica del preescolar. 3 ed. Espanha: CINCEL.

Loubet, M. P. (1979). A estética e a educação. Ciências Humanas, 3(10), 27-29.

Lowenfeld, V. (1977). Desenvolvimento da capacidade criadora. São Paulo: Mestre Jou.

Neiva-Silva, L. (2003). Expectativas futuras de adolescentes em situação de rua: um estudo autofotográfico. Dissertação de Mestrado Não-Publicada, Curso de Pós-Graduação em Psicologia do 
Desenvolvimento, Universidade Federal do Rio Grande do Sul. Porto Alegre.

Oliveira, M. K. (1995). Vigotsky: aprendizado $e$ desenvolvimento, um processo sócio-histórico. São Paulo: Scipione.

Peralta, C.H.G. (1998) A arte do grafismo infantil e a construção simbólica. (Manuscrito Não-Publicado).

Portugal, G. (1992). Ecologia e Desenvolvimento Humano em Bronfenbrenner. Aveiro: CIDINE.

Postic, M. (1993). O Imaginário na Relação Pedagógica. (E. S. Abreu, Trad), Rio de Janeiro: Jorge Zahar.

Vygotsky, I. (1966, $3^{\mathrm{a}}$ ed.). La imaginación y el arte en la infancia. Madrid: Ediciones Akal.
Yunes, M. A. M., Miranda, A. T. E \& Cuello, S. E. S. (2004). Um olhar ecológico para os riscos e as oportunidades de desenvolvimento de crianças e adolescentes institucionalizados. Em: S. H. K. (Org.), Ecologia do Desenvolvimento Humano: pesquisa $e$ intervenções no Brasil. Casa do Psicólogo, São Paulo.

Yunes, M. A. M. (2001) A questão triplamente controvertida da resiliência em famílias de baixa renda. Tese de Doutorado Não-publicada. Programa de Pósgraduação em Educação, Psicologia da Educação. Pontifícia Universidade Católica de São Paulo.

Recebido em 05/07/2004 Aceito em 30/10/2004

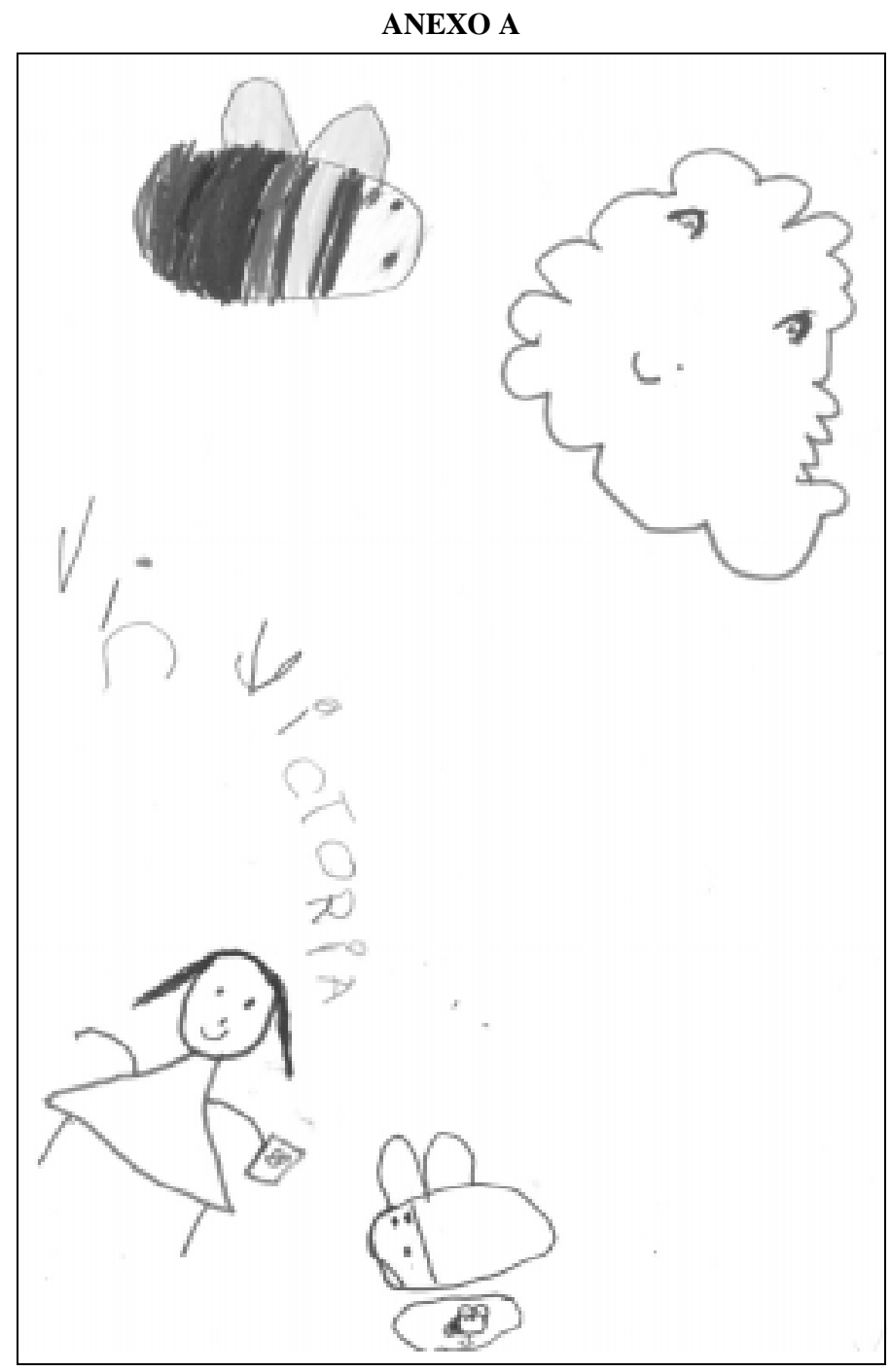

Endereço para correspondência: Luciane Germano Goldberg. Caixa Postal 32, Porto das Dunas, CEP 61700-000, Aquiraz-CE. E-mail: lugoldberg@ hotmail.com 